\title{
Ventilator-associated pneumonia prevention: one good turn does not always deserve another
}

Pedro Póvoa ${ }^{1,2^{*}} \mathbb{D}$, Thiago Lisboa ${ }^{3,4}$ and José-Artur Paiva ${ }^{5,6,7}$

@ 2017 Springer-Verlag GmbH Germany and ESICM

Ventilator-associated pneumonia (VAP) is a frequent complication of patients undergoing invasive mechanical ventilation and its occurrence is associated with considerable morbidity and mortality [1-3]. The key factor in the pathogenesis of VAP is the endotracheal tube (ETT) [4]. Its presence compromises the natural anatomical barriers (larynx) and functional mechanisms (mucus clearance and cough), and it expedites the formation of biofilm as well as macro- and microaspiration of oropharyngeal secretions. As a result, several strategies have been successfully implemented, namely subglottic secretion drainage or cuff pressure control $[3,4]$.

One of the current recommendations for VAP prevention is elevation of the head of bed to $30-45^{\circ}$ to prevent the reflux of colonized gastric contents that has a potential role in VAP pathogenesis. This strategy has been evaluated in three randomized controlled trials (RCT) enrolling 337 patients, one positive and two negatives [57], and in a meta-analysis pooling these three studies that found a significant impact on prevention [8]. However, the quality of evidence is low, being considered a basic practice because of its simplicity, ubiquity, low cost, and potential benefit [3].

Simultaneously, we can conceive that in a patient with an ETT, any position above horizontal increases the gravitational forces exerted by subglottic secretions above the cuff and, consequently, the risk of aspiration [9]. The results of several experimental studies challenged the recommendation of the semirecumbent position in VAP

\footnotetext{
${ }^{*}$ Correspondence: pedrorpovoa@gmail.com

1 Polyvalent Intensive Care Unit, Unidade de Cuidados Intensivos Polivalente, Hospital de São Francisco Xavier, Centro Hospitalar de Lisboa Ocidental, Estrada do Forte do Alto do Duque, 1449-005 Lisbon, Portugal Full author information is available at the end of the article
}

prevention. In animal models, the Trendelenburg position showed an increase in mucus clearance, decreasing aspiration and consequently VAP rates $[9,10]$. With this rationale an RCT was designed to evaluate this hypothesis.

In the GRAVITY-VAP trial, recently published in Intensive Care Medicine, Li Bassi, Panigada, and co-workers performed a multicenter, multinational RCT to assess the impact of the lateral Trendelenburg position (LTP) vs. semi-recumbent position (SRP) in VAP incidence [11]. A total of 395 patients $(N=194$ LTP; $N=201$ SRP) were included. The trial was prematurely ended because of low incidence of VAP, lack of benefit in secondary outcomes, and serious adverse events (SAE). The incidence of microbiologically confirmed VAP was $0.5 \%$ in LTP and $4.0 \%$ in the SRP patients $(P=0.04)$; however, the rate of SAE was significantly higher in the LTP group, namely transient oxygen desaturation and hemodynamic instability. In addition, mortality (ICU, hospital, and day 28) was non-significantly higher in the LTP group, ranging from an absolute difference of $6.5 \%$ in ICU mortality to $4.5 \%$ in day 28 mortality. Moreover, in spite of the risk difference of $-7.6 \%(P=0.02)$ in microbiologically confirmed VAP in the LTP group, antibiotic consumption was similar in both groups. This may be due to the higher incidence of clinically suspected VAP in LTP patients with pulmonary infiltrates at the time of enrollment, encouraging BAL assessments, and empirical antibiotic prescription or to the fact that LTP patients had more ventilator-associated tracheobronchitis (VAT), promoting antibiotic treatment directed at this entity. As prevention of aspiration-a paramount mechanism for both VAP and VAT-is the rationale behind LTP, this strategy would be expected to reduce the incidence of both infections. In our opinion, consumption of antibiotics should be an important

\section{望


outcome variable for studies assessing new preventive strategies for healthcare-associated infections.

This is an example of a well-designed RCT, in which safety was carefully monitored. The apparent discrepancy between the lower incidence of VAP and higher incidence of SAE could explain the absence of clinical impact of this intervention. These results raise two methodological considerations that deserve to be discussed. First, the potential random nature of the reduced rate of microbiologically confirmed VAP in the intervention group as the study was stopped early. Although study interruption was not due to benefit, it is well known that trials stopped early, on average, overestimate the effect of an intervention and that the apparent overestimation is larger in smaller trials [12]. The high rate of SAE seems incompatible with a positive result, suggesting that the study is clearly underpowered. Also, the fragility of positive results regarding the main outcome-microbiologically documented VAPappears to be high. Walsh et al. [13] published an interesting exercise creating a fragility index for clinical trials to identify the number of events required to change statistically significant results to non-significant results. In Li Bassi and Panigada's study, the fragility index is 1 : only one event-change (microbiologically documented VAP) is required to change the significant result.

However, this trial brings new data that deserves to be further discussed. The lower incidence of VAP with LTP (eight times lower) reinforces the concept that macroand microaspiration of oropharyngeal secretions have a key role in the pathogenesis of VAP [4].

There is also new data from the interpretation of the SAE, namely in two areas. The central nervous system seems to have been involved in some causes of death and was one of the reasons behind the decision to terminate the RCT early. This occurred in spite of the fact that patients with raised intracranial pressure (ICP) were excluded by the study protocol. However, LTP is always associated with a persistent non-quantifiable increase in ICP, with unpredictable consequences.

Secondly, the change in chest compliance and intrathoracic pressure as a consequence of LTP may be a problem, especially in the presence of raised intra-abdominal pressure (IAP). In the supine position, on average, $40 \%$ of the IAP is transmitted to the intrathoracic pressure and also changing chest wall compliance [14]. This effect can increase the risk of basal atelectasis, worsening of gas exchange, and arterial blood gases.

Finally, the incidence of delirium as a marker of acute brain dysfunction [15] was not evaluated. We all know that increased duration and degree of sedation, namely in LTP patients, in particular with benzodiazepines, is associated with increased risk of acute brain dysfunction, namely delirium, and this could potentially be associated with the observed poor outcomes.

In conclusion, we should pursue efforts and research to improve our knowledge of the pathophysiology of VAP as well as to design RCT to assess the safety and efficacy of new preventive strategies. But it seems that turning the head down is not a safe turn!

\begin{abstract}
Author details
${ }^{1}$ Polyvalent Intensive Care Unit, Unidade de Cuidados Intensivos Polivalente, Hospital de São Francisco Xavier, Centro Hospitalar de Lisboa Ocidental, Estrada do Forte do Alto do Duque, 1449-005 Lisbon, Portugal. ${ }^{2}$ NOVA Medical School, CEDOC, New University of Lisbon, Lisbon, Portugal. ${ }^{3}$ Critical Care Department and Infection Control Committee, Hospital de Clínicas de Porto Alegre, Porto Alegre, Brazil. ${ }^{4}$ Rede Institucional de Pesquisa e Inovação em Medicina Intensiva (RIPIMI), Complexo Hospitalar Santa Casa de Misericórdia, Porto Alegre, Brazil. ${ }^{5}$ Emergency and Intensive Care Department, Centro Hospitalar São João, Porto, Portugal. ${ }^{6}$ Faculty of Medicine, University of Porto, Porto, Portugal. ${ }^{7}$ Grupo de Infecção e Sepsis, Porto, Portugal.
\end{abstract}

\section{Compliance with ethical standards}

\section{Conflicts of interest}

The authors declare no conflict of interest related to this topic.

Received: 4 June 2017 Accepted: 7 June 2017

Published online: 22 September 2017

\section{References}

1. Martin-Loeches I, Povoa P, Rodriguez A, Curcio D, Suarez D, Mira JP, Cordero ML, Lepecq R, Girault C, Candeias C, Seguin P, Paulino C, Messika J, Castro AG, Valles J, Coelho L, Rabello L, Lisboa T, Collins D, Torres A, Salluh J, Nseir S, TAVeM study (2015) Incidence and prognosis of ventilator-associated tracheobronchitis (TAVeM): a multicentre, prospective, observational study. Lancet Respir Med 3:859-868

2. Kalil AC, Metersky ML, Klompas M, Muscedere J, Sweeney DA, Palmer LB, Napolitano LM, O'Grady NP, Bartlett JG, Carratala J, El Solh AA, Ewig S, Fey PD, File TM Jr, Restrepo MI, Roberts JA, Waterer GW, Cruse P, Knight SL, Brozek JL (2016) Management of adults with hospital-acquired and ventilator-associated pneumonia: 2016 clinical practice guidelines by the Infectious Diseases Society of America and the American Thoracic Society. Clin Infect Dis 63:e61-e111

3. Klompas M, Branson R, Eichenwald EC, Greene LR, Howell MD, Lee G, Magill SS, Maragakis LL, Priebe GP, Speck K, Yokoe DS, Berenholtz SM (2014) Strategies to prevent ventilator-associated pneumonia in acute care hospitals: 2014 update. Infect Control Hosp Epidemiol 35(2):S133-S154

4. Li Bassi G, Ferrer M, Ranzani OT, Marti J-D, Berra L, Fernandez L, Torres A (2012) Prevention of VAP: role of the artificial airway, body position and setting the ventilator. Eur Respir Monogr 55:153-168

5. Drakulovic MB, Torres A, Bauer TT, Nicolas JM, Nogue S, Ferrer M (1999) Supine body position as a risk factor for nosocomial pneumonia in mechanically ventilated patients: a randomised trial. Lancet 354:1851-1858

6. van Nieuwenhoven CA, Vandenbroucke-Grauls C, van Tiel FH, Joore HC, van Schijndel RJ, van der Tweel I, Ramsay G, Bonten MJ (2006) Feasibility and effects of the semirecumbent position to prevent ventilator-associated pneumonia: a randomized study. Crit Care Med 34:396-402

7. Keeley L (2007) Reducing the risk of ventilator-acquired pneumonia through head of bed elevation. Nurs Crit Care 12:287-294

8. Alexiou VG, lerodiakonou V, Dimopoulos G, Falagas ME (2009) Impact of patient position on the incidence of ventilator-associated pneumonia: a meta-analysis of randomized controlled trials. J Crit Care 24:515-522 
9. Li Bassi G, Zanella A, Cressoni M, Stylianou M, Kolobow T (2008) Following tracheal intubation, mucus flow is reversed in the semirecumbent position: possible role in the pathogenesis of ventilator-associated pneumonia. Crit Care Med 36:518-525

10. Panigada M, Berra L, Greco G, Stylianou M, Kolobow T (2003) Bacterial colonization of the respiratory tract following tracheal intubation-effect of gravity: an experimental study. Crit Care Med 31:729-737

11. Li Bassi G, Panigada M, Ranzani OT, Zanella A, Berra L, Cressoni M, Parrini V, Kandil H, Salati G, Selvaggi P, Amatu A, Sanz-Moscosi M, Boagioni E, Tagliaferri F, Furia M, Mercurio G, Costa A, Manca T, Lindau S, Babel J, Canava M, Chiurazzi C, Marti J-D, Consonni D, Gattinoni L, Pesenti A, Weiner-Kronish J, Ballotta A, Salsi P, Livigni S, lotti G, Fernandez J, Girardis M, Barbagallo M, Moise G, Antonelli M, Caspani ML, Vezzani A, Meybohm P, Gasparovic V, Geat E, Amato M, Niederman M, Kobolow T, Torres A, for the GRAVITY-trial network (2017) Randomized, multi-center trial of lateral Trendelenburg versus semi-recumbent body position for the prevention of ventilator-associated pneumonia. Intensive Care Med. doi:10.1007/ s00134-017-4858-1
12. Guyatt GH, Briel M, Glasziou P, Bassler D, Montori VM (2012) Problems of stopping trials early. BMJ 344:e3863

13. Walsh M, Srinathan SK, McAuley DF, Mrkobrada M, Levine O, Ribic C, Molnar AO, Dattani ND, Burke A, Guyatt G, Thabane L, Walter SD, Pogue J, Devereaux PJ (2014) The statistical significance of randomized controlled trial results is frequently fragile: a case for a fragility index. J Clin Epidemiol 67:622-628

14. Akoumianaki E, Maggiore SM, Valenza F, Bellani G, Jubran A, Loring SH, Pelosi P, Talmor D, Grasso S, Chiumello D, Guerin C, Patroniti N, Ranieri VM, Gattinoni L, Nava S, Terragni PP, Pesenti A, Tobin M, Mancebo J, Brochard L, PLUG Working Group (Acute Respiratory Failure Section of the European Society of Intensive Care Medicine) (2014) The application of esophageal pressure measurement in patients with respiratory failure. Am J Respir Crit Care Med 189:520-531

15. Salluh Jl, Wang H, Schneider EB, Nagaraja N, Yenokyan G, Damluji A, Serafim RB, Stevens RD (2015) Outcome of delirium in critically ill patients: systematic review and meta-analysis. BMJ 350:h2538 